\title{
State of Civil Society Development in Mongolia
}

\author{
T. U ndarya (M ongolia)
}

$\mathrm{M}$ ongolia's civil society has been much praised by observers, mostly foreign, for its strength and vibrancy. While these glowing accounts do have some merit, it is important to take a more sober look at not so conducive environment - political, cultural, economic and financial,- which could severely undermine the future of Mongolia's civil society. Yet, given the current position of Mongolia, standing to gain from its mining boom, the presence of a strong, well resourced, effective and ethical civil society may be the key factor for determining the country's course towards equitable and democratic development or essentially a corrupt police state with a small elite ruling over the poor masses.

With this thought in mind, this article will review the development of the Mongolian civil society, particularly its environment and structure. The article will rely on the latest available comprehensive study of civil society in Mongolia, produced using the CIVICUS's Civil Society Index (CSI) methodology. ${ }^{1}$ Although the CSI study was conducted in 2004-2005, civil society stakeholders agree that its main findings still hold. ${ }^{2}$ Whenever necessary and possible, the study findings shall be updated with more recent data and analysis. Given the diversity and complexity of the broader civil society field, and considering the vital role played in this field by human rights (including women's rights) and pro-democracy advocacy NGOs, the article will focus more on this particular sub-field.

1 Center for Citizens' Alliance (former CEDAW Watch)/International Civil Society Forum Ulaanbaatar Secretariat, State of Civil Society in Mongolia. 2004-2005 Civil Society Index Report for Mongolia (Ulaanbaatar, 2006). Also available online at: https://cswatch.org/ user/37/article/civicus-civil-society-index-country-report-mongolia. The Civil Society Index exercise was implemented by the Center for Citizens' Alliance as part of the follow-up activities aimed at implementing the recommendations of the International Civil Society Forum-2003 and the Fifth International Conference of New and Restored Democracies (ICNRD-5).

2 Hence, civil society stakeholders to use the study as the basis for the main presentation from civil society at the 2011 National Civil Society Forum (March 9-10), so far the largest civil society-government dialogue on the state of civil society and state policy concept on supporting the sustainable development of civil society. 


\section{CSI's analytical framework and methodology}

The CSI methodology conceptualizes civil society as "the arena outside of the family, the state and the market where people associate to advance common interests," emphasizing the political nature of this field. ${ }^{3}$ It assesses the state of civil society in a given country on four key dimensions - structure, environment, values and impact, - which are further divided into sub-dimensions and then into a total of over 70 indicators. The data are gathered through a mix of quantitative and qualitative methods from a variety of sources. Each sub-dimension is assessed on a scale from 0 to 3 points based on indicators, then sub-dimension scores are integrated into dimension scores and the result is presented as a Civil Society Diamond. ${ }^{4}$

\section{Assessment of Mongolia's Civil Society}

Contrary to the common highly optimistic perception of the state of civil society in Mongolia, the study produced a rather small, under-developed diamond (see Figure 1), indicating a structurally rather weak civil society, operating in a largely disabling environment, with moderate impact but driven by its commitment to positive values.

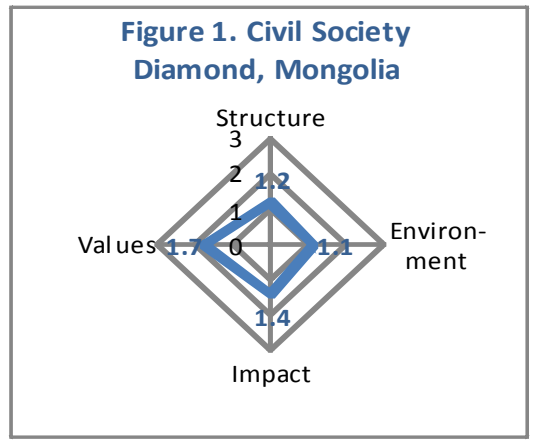

\section{Structure}

This dimension looks at the overall size, strength and vibrancy of civil society in human, organizational and economic terms. The score of 1.2 indicated a somewhat small-sized and weakly structured civil society, with higher indicators of CSO membership (due to traditional membership in main political parties, trade unions and mass organizations like the Red Cross Association) but lower

3 To this day, this definition is widely used by civil society activists in their public education and advocacy work. It is useful in distinguishing civil society as a non-profit voluntary field that promotes common interests from the state as an entity that has the monopoly of coercive means in a society, profit-oriented market, and family with its focus on private concerns. The definition remains useful in highlighting independence from the state as a key feature of civil society and for emphasizing civil society ethics.

4 For more information on the CSI methodology, see Center for Citizens' Alliance (2006), pp. 13-21. 
indicators for the depth and quality of participation, nonpartisan political activism, charitable giving and volunteerism.

The study found high concentration of civil society organizations and activities in the capital city, and to a lesser extent in aimag centers, with rural civil society sorely under-developed due to the lack of financial support and information. Herders, the poor and ethnic and religious minorities were found to be generally under-represented in civil society although

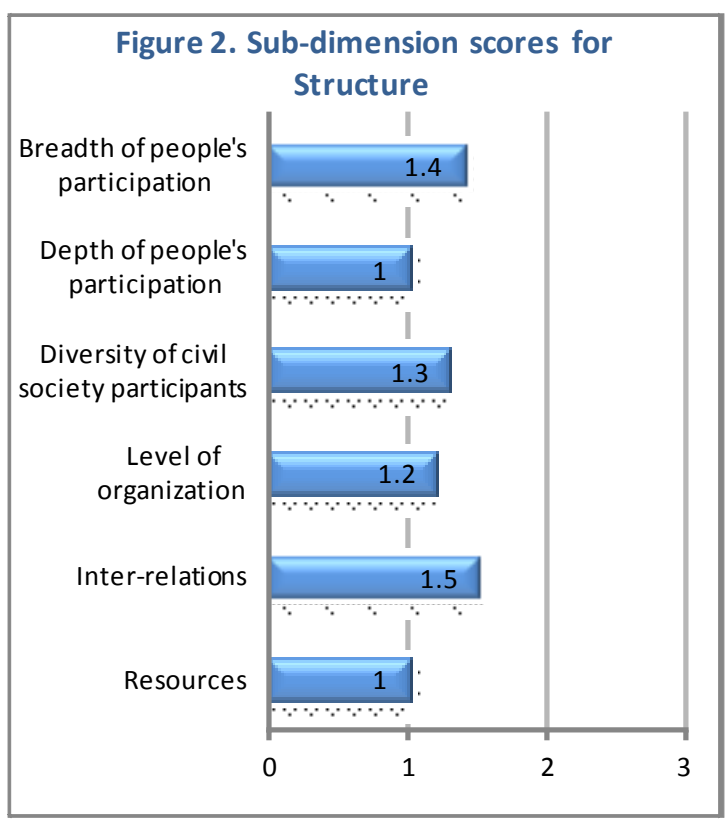
emerging grassroots activism was noted in response to environmental challenges. Women figured prominently at both membership and leadership levels, with the exception of political parties, business associations and local councils. They were also noted as leading in the more established advocacy NGOs.

The study noted important trends towards greater inter- and intra-sectoral cooperation among CSOs, but the effectiveness and legitimacy of umbrella organizations was contentious, due to the predominance of rather hierarchical structures inherited from the socialist period. In terms of resources, inherited mass organizations were at significant advantage, able to access state resources at national and local levels, some owning large buildings (e.g., The Youth Federation, and Peace and Friendship Association). By contrast, human rights and pro-democracy NGOs, in both urban and rural areas, were financially weak, almost exclusively dependent on project funding from international organizations.

On some of these sub-dimensions, Mongolian civil society has made significant achievements. There has been growing understanding of and support for non-partisan political activism, cooperation across party lines for common interests, and somewhat more active volunteerism, especially among youth. While the distribution of civil society activism is still very far from even, there is growing civil society organization in rural areas, going to soum levels. Examples include artisanal miners' NGOs, savings and self-help community based groups, environmental groups, and herders' collective struggles in mining-affected areas. 
Civil society is much more diverse than before, with more active engagement of marginalized groups including young women, teenage mothers, ethnic minorities, LGBT groups, herders, artisanal miners, teachers, people living with disabilities, and children.

Impressive progress has been made in the level of organization, with the establishment of new forms of collective bodies such as networks, open forums, platforms and coalitions. Examples include the "July $1^{\text {st }}$ Coalition" and the "Human Rights under the State of Emergency Monitoring and Protection Coalition" formed in 2008. The latter mobilized around 150 volunteers consisting of civil society activists, youth, students, and lawyers to undertake human rights documentation and provide free legal aid to victims detention centers and hospitals. Both coalitions were led by women's rights activists.

The NGO Forum for the Universal Periodic Review was established as an open platform for all NGOs willing to contribute and participate. Facilitated by the Center for Human Rights and Development, the forum successfully integrated diverse and representative participation of social groups and civil society sectors, including ethnic and sexual minority groups, and supported their capacitybuilding and solidarity. Reporting on the Civil and Political Rights and, later, on the Economic, Social and Cultural Rights was also organized in a similar fashion in a thoroughly participatory and inclusive fashion. Similar efforts for ensuring diverse representation and inclusion were successfully made through other mechanisms including the MONFEMNET National Network, the newly established "All for Education!" National Civil Society Coalition, NGO Open Forum for Development Effectiveness, and Food Sovereignty Coalition.

These forums, networks and coalitions present a new and so far highly effective and ethical forms of collective action, cooperation and solidarity. They drastically depart from the old socialist style vertical structures, which unevenly distribute power and resources and rely on a command system. The new forms of organization are consciously based on horizontal, mutually supportive yet accountable power-sharing schemes, careful nurturing of a caring, egalitarian and democratic culture, and strongly emphasise shared and deeply internalized values, principles and goals informed by democratic ideals, human rights, and gender equality. Aside from organizational innovations, human rights/women's rights and advocacy NGOs have successfully created new public spaces through their discussion platforms, conventions and social media forums, facilitating multistakeholder dialogues and cooperation, raising citizens' political consciousness and opening avenues for individual engagement.

These new, democratic structures and spaces are consciously nurtured and carefully expanded to foster broad-based movements for social change, characterized by sound analysis of the status quo, clear vision of the desired 
changes, solidarity and firm commitment. As part of this goal and stemming from an intersectional analysis of oppressive power structures, human rights and gender equality NGOs have paid significant attention to strengthening not only intrasectoral but also inter-sectoral linkages, solidarity and collective action. This is strengthened through the emphasis on diversity, participation, representativeness and inclusion and more strategic interventions.

Higher level of networking and organization is also evident from the formation of aimag-level and sectoral civil society networks and councils. Nearly all aimags have civil society networks and some have formed women's networks to work more effectively for social change. With the support of the Swiss-funded Sustainable Artisanal Minig project, artisanal miners' NGOs are working to form a national Federation to step up their advocacy efforts. At some ministries, civil society councils were formed to facilitate dialogue and cooperation in that sector.

In the absence of a support infrastructure for civil society development, the more established NGOs have functioned as training and resource centers, mentors, incubators, and facilitators for the smaller groups and organizations. They have also functioned as policy think tanks and helped develop analytical and research capacity of various stakeholders, including media and government. There is much higher degree of professionalization among NGOs, prominent examples including the National Center against Violence, Gender Equality Center, Open Society Forum, and the Mongolian Education Alliance. In terms of the expertise in their fields, they are ahead of the Government and often ahead of international organizations.

The Mongolian civil society, especially the Ulaanbaatar-based human rights and advocacy NGOs, are well integrated into the regional and international civil society processes, with particularly strong ties with the Asia-Pacific, North America, Western Europe but also, through the support of the OSI network, with East and Central Europe and Central Asia. Mongolian activists often actively contribute at leadership levels in regional and international networks. However, the situation is drastically different for aimag and soum NGOs due to language barriers and resource limitations. It would be catalytic to facilitate local NGOs' participation in international processes but so far there have been few such opportunities.

Mongolian civil society, especially the human rights field, has thus accumulated significant programmatic experience, strengthened its national and international networks, fostered internal cohesion and solidarity, linked up with the grassroots, and, in some cases, has developed working relations with state institutions. However, where no to very little progress has been made is in their financial sustainability and, consequently, in their institutional strength. The funding environment has never been very conducive, especially for advocacy 
NGOs. Government provided no support while international organizations have almost exclusively provided limited project funding on an ad hoc basis. Except for very few organizations, advocacy, human rights and women's rights NGOs have received no core funding. At the same time bilateral agencies and development organizations have consistently provided generous funding to international NGOs, from the aid funds for Mongolia's development. Thus, despite the popular rhetoric of the importance of civil society, the international community and the government have failed to provide adequate support to build sustainable institutions and develop an adequate support infrastructure for civil society development in Mongolia.

As a result, the future of Mongolian civil society remains uncertain as adequate government support shall not materialize in the recent future, given the current political situation, while the middle class remains thin and poverty wide-spread, rendering local private fundraising unrealistic as a sufficient source of support. As social inequalities persist or even deepen while Mongolia's economy grows fast (GDP growth at 17.2\% in 2012, GDP per capita reaching 892 USD the same year from 528 USD in 2004) $)^{5}$ and Mongolia is classified as a lower middle income, international development agencies are likely to even further reduce their support for civil society. Should available funding continue to be primarily channelled to foreign NGOs, despite internationally agreed upon principles of development cooperation, calling for national ownership, capacity-building and involving national civil society as development partner in its own right, the national civil society may not sustain itself for long or, if it does, be effective in influencing the development of the country. Until today, civil society has run on its commitment, rather than adequate support but this steam may not be sufficient into the third and fourth decades of post-socialism.

\section{Environment}

The environment dimension looks at the overall political, social, economic, cultural and legal environment in which civil society exists and functions. The score of 1.1. indicates a rather disabling environment. In terms of the political context, the following were stressed as factors impeding the development of civil society:

- State still domineering, largely authoritarian and intrusive.

- Wide-spread corruption in public office.

- Weak and poorly representative multi-party system, controlled by the wealthy, parties lacking internal democracy, opposition underdeveloped.

5 International Monetary Fund, IMF Fiscal Monitor 2013. Fiscal Adjustment in an Uncertain World (www.imf.org/ FiscalMonitor). 
- Mounting electoral fraud and excessive influence of money increasingly eroding the legitimacy of elections.

- Insufficiently independent judiciary.

- Weak local democracy, highly centralized state power.

- State services largely inefficient, unresponsive and non-transparent.

Further, the study concluded that frequent violations of human rights, widespread poverty and unemployment, absence of a strong middle class, considerable urbanrural development gap and significant social problems, such as alcoholism, crime and violence further obstruct civil society's

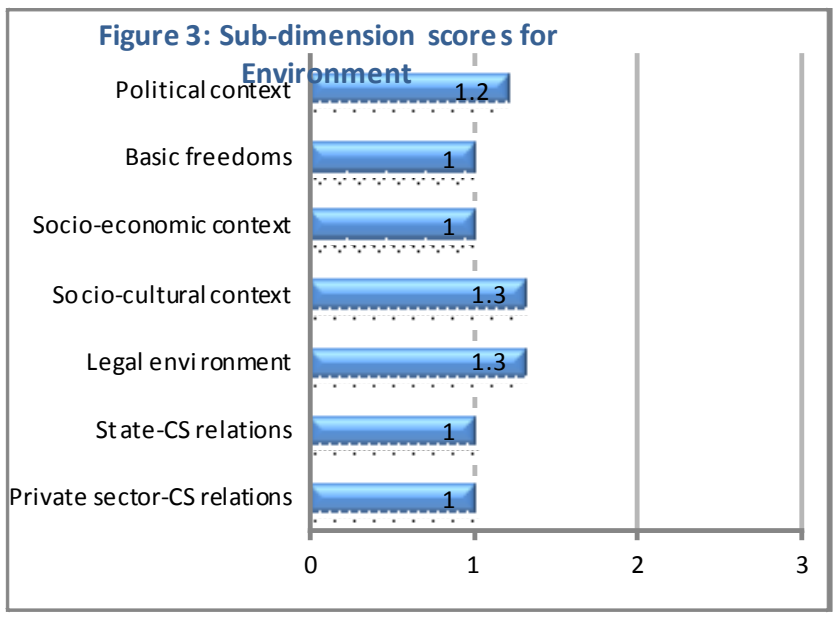
development. On the whole, both state-civil society and private sector-civil society relations were assessed as largely unproductive though they differ by branch and level of government, highly dependent on the attitude of a given official, and the type of the CSO concerned. State-centered and passive mentality among citizens and public servants' negative attitudes towards civil society ${ }^{6}$ were cited as cultural obstacles.

However, the legal framework for the operation of most CSOs, including political parties, human rights NGOs and anti-corruption and pro-democracy mass movements was assessed as rather liberal, based on the 1997 NGO law and backed by the 1992 Constitution.

\section{Progress since 2005}

While overall these findings still hold, there have been a number of important positive developments since the CSI study, such as the abolishment of the capital

6 Quite recently, an activist reported overhearing public servants at the Education Ministry tell each other that they should stay away from NGO types as the latter have "negative energy." Another activist reported hearing government officials describe NGO activists as "men and women with big mouths and talking nonsense." Just last week a district statistical officer requested data from a NGO within an unreasonably short period of time and threatened with legal sanctions should the NGO fail to do as bidden, without introducing his name or position or giving any reference to legal acts that would obligate NGOs to comply with such a request. These and numerous other cases clearly demonstrate the deeply ingrained negative attitude among public servants against civil society. 
punishment and passing of the Gender Equality Law. Further, a number of important laws and regulations have been passed (see the list below) to improve transparency, accountability and responsiveness of the government and broaden the space for civil society oversight.

- Law on Information Transparency and the Right to Information (2011.06.16)

- Law on Managing and Preventing Conflict of Public and Private Interest in Public Service (2012.01.19)

- Regulation on Ensuring Budget and Financial Transparency (2012.01.18)

- Article 6.5 on the implementation of the budget transparency principle, providing for citizen participation, in the amended Law on Budget (2011.12.23)

While these laws have yet to be put to the test of meaningful implementation, there have been other important developments such as concerted efforts to strengthen professionalism and independence of the judiciary, led by the current President's Office, and efforts to improve the justice system so as to ensure human rights, led by the Ministry of Justice and Home Affairs under the current minister. Furthermore, the Anti-Corruption Agency has been working more rigorously, uncovering a number of high-profile corruption cases such as those related to MIAT, General Taxation Office and the ex-president N.Enkhbayar. Trials of the latter were highly politicized but nevertheless resulted in criminal sanctions, regarded by many as too lenient, but nevertheless, one might argue, helpful in sending a public message on accountability for high-level officials. Most recently, the Vice-Speaker of the Parliament stepped down over a public outrage for his failure to disclose sizeable funds in his Swiss bank account in his Income and Assets Declaration. It is yet to be seen if he is held fully accountable for this failure to comply with the law. ${ }^{7}$

Following the 2009 Presidential Election, a number of initiatives by the President Ts.Elbegdorj have been favorable to civil society, including the creation of a new post of a Presidential Advisor on Human Rights and Citizen Participation and launching of Citizens' Halls under the President's Office in Ulaanbaatar and at local levels. While there are serious shortcomings in the President's Office's approach to citizen participation (mainly due to a major lack of understanding of the important role of civil society organizations and the importance of meaningful facilitation of citizen inputs), these measures nevertheless opened new channels

7 On a darker side, high-level government and police decision-makers guilty for the human rights violations and the death of civilians during the July 1 events and the 4-day State of Emergency have yet to be held properly accountable. Similarly, the 1998 case of the murder of a prominent politician S.Zorig remains unresolved. 
of dialogue between decision-makers, citizens and civil society groups ${ }^{8}$ and raised the discourse on human rights to a higher level, which was particularly important following the July 1 mass violations of human rights during the postelection public protests.

A very important step towards strengthening Mongolia's democracy was the Government-NGO cooperation on developing a State Policy Concept on Supporting Sustainable Development of Civil Society through the working group formed under the previous Prime Minister ${ }^{9}$ and continued cooperation of CSOs with the Minster of Justice and Home Affairs on reforming the NGO legislation. The drafting of the State Policy Concept was a result of several years of NGO advocacy aimed at ensuring that the Mongolian state in fact fulfills its primary obligation to serve the supreme goal of Mongolia, as stated in the 1992 Constitution, to develop a humane, civil and democratic society, by supporting and investing in the sustainable development of civil society. The Policy Concept is expected to set a progressive framework for NGO law reform, open opportunities for implementing state-funded programs on supporting civil society initiatives, and provide additional ammunition for NGO advocacy. The drafting of the State Policy was led by civil society leaders and public discussions were held throughout the country, culminating in the National Civil Society Forum, to date the largest event on civil society in Mongolia, held on March 9-10, 2012. The draft was subsequently approved by the Cabinet and passed onto the parliament for discussion and approval. ${ }^{10}$

8 A number of advocacy NGOs have fruitfully used the Citizen's Hall for instigating public discussions on policy issues, raising public awareness and lobbying decision-makers. Also, the Presidential Advisor on Human Rights and Citizen Participation facilitated the first breakfast meeting of women's rights activists and representatives of diverse groups of women (young women, teenage mothers, artisanal miners, herders, women with disabilities, ethnic and sexual minority women, etc.) with the President on March 7, 2013, with a square focus on women's rights violations, their root causes, and women's analysis of the current political, economic and cultural distortions.

9 Order of the Prime Minister of Mongolia No.17, 11 March 2011.

10 Due to the elections, this process has been stalled but is about to resume with the formation of a new CSO-Government working group formed at the Ministry of Justice to work more systematically on the Policy Concept and NGO-related legislation. 


\section{Concept of the Development of Civil Society ${ }^{11}$ (draft submitted to the State Great Khural by the Cabinet)}

Section 1 on general provisions lays out the philosophical basis for the promotion of civil society, firmly grounded in democratic values, reinforcing the spirit of the democratic Constitution, and acknowledging the need for further deepening democracy and fostering democratic norms in social relations, particularly as Mongolia enters a new stage of its economic development. Premised on the notion that the very existence of the State and state power stems from the citizenry, the document insists on the principle of equality, not dominance, in the partnership between government and civil society. The document reaffirms that a capable, strong and independent civil society is an expression and guarantee of Mongolia's democracy.

Section 2 defines key concepts related to civil society, conceptualizing the latter as "activities carried out locally, sectorally or nationally by individuals or formal and informal groups of individuals who have united voluntarily on the basis of common views or interests, for the purpose of contributing to political, economic, social and cultural development" and as "the arena outside of the family, the state and the market where people associate on a voluntary basis or act individually to advance common interests, goals or values." It stresses articulating citizens' interests and demands, defending citizens' rights and providing services as the three main functions of civil society, articulates that "freedom from any pressure, coercion or influence on the part of the government is an essential condition" for meaningful contribution of civil society, and emphases that "supporting the development of civil society organizations and other formal and informal groups is instrumental to the growth and maturity of civil society."

Section 3 lists values and principles shared by the government and civil society, which form the essential foundation for effective cooperation. The values include: healthy and safe environment, human rights and fundamental freedoms, rule of law, diversity and inclusiveness, tolerance, social cohesion and justice, and philanthropy. The principles include: equal opportunity, mutual respect, promotion of diversity and inclusiveness, respect for independence of CSOs, policy dialogue, meaningful participation, transparency, accountability, efficiency, and freedom from corruption.

Section 4 establishes a framework for government policy and activities on civil society, defining the promotion of public interest by way of increasing the potential of civil society and civil society organizations and strengthening cooperation between State and civil society as the ultimate goal of the state policy. It defines the concepts of social capital, social innovation and social economy as underpinning government support and identifies promotion of democratic political culture, expansion of citizen participation, and strengthening of cooperation between State and civil society as the 3 strategic areas of intervention.

Section 5 lays out the principles and systems for the implementation of the policy concept and Section 6 defines procedures for adopting and amending the policy concept.

11 Government of Mongolia, Draft Concept of the Development of Civil Society (2012.04.20). 


\section{Persistent concerns and negative trends}

Despite these positive efforts, serious concerns remain over perverse institutionalization, entrenchment of undemocratic practices and erosion of the 1992 Constitution through frequent amendments informed by narrow political interests. The constitutional principle of checks and balances remains violated as the Constitutional amendments permitting MPs to concurrently serve as Ministers and the now entrenched practice of MPs to allocate large sums from state budget for their nebulous constituency-building goals blur the boundaries between the legislative and executive branches and weaken the parliamentary capacity to oversee the work of the executive.

Political parties are controlled by the wealthy, leaving the vast majority of Mongolians, especially women, children, ethnic and sexual minorities, people with disabilities, the poor and the rural populations unrepresented and manipulated through controlled media and vote-buying. Thus, Mongolia's democracy is more and more a bourgeois, rather than popular, democracy. This situation is in part maintained through the election laws, which afford significant advantages to major parties, incumbents and the moneyed candidates, forcing smaller parties, women and independent candidates to compete on highly unfavorable terms. Quite perniciously, through the limitations on the campaigning period, the laws in fact prevent any sound analysis and comparison of election platforms, substantive deliberations and informed choice. ${ }^{12}$

State services are often inefficient, ineffective and unresponsive. The government capacity developing and implementing evidence-based policies continues to be weak, resulting in significant harm for the people. Prime examples are ambitious and frequent top-down reforms and reversals in the education system, with the current Government's "Correct Mongolian Child" policy being the latest in a long line of inappropriate autocratic policies, preceded by the elitist, enormously expensive and broadly advertised Cambridge education program. ${ }^{13}$

The state institutions still lack sound understanding of values and principles of democracy, human rights and gender equality, resulting in state actions which directly violate these principles and overtly discriminate against specific groups of people on the basis of gender, sexual orientation, or income level. In fact, despite the recent increase in the number of women MPs (from 3 to 11 out of 76 in the 2012 election), promulgation of the Gender equality Law, obligations under CEDAW and other international human rights treaties that emphasize

12 The parliamentary elections, held every 4 years, would be announced merely 2 months prior to the election date and contestants are required to popularize their election platforms barely 17 days prior to the election date. In 2008, one party launched their platform only a week before the election day!

13 For more information on education policies, contact the "All for Education!" National Civil Society Coalition (info@all4education.mn). 
gender equality, there is an increasingly strong trend towards masculinization of the state and political space.

This was demonstrated by the 2011 Ritual of Lighting the State Fire Burning initiated by a male MP and supported by the President's Office, Cabinet and Parliament on the whole. A Presidential Decree was issued calling on all governmental and non-governmental organizations, economic entities and households "to light their hearth fire in order to strengthen the hiimori and spirit of the state and the people and respect the national tradition." 14 The cabinet approved spending of 360 million tugrugs for this ritual. The ritual was carried out in the Cereminal Ger inside the Government house, without a single women present. While no written orders were issued to exclude women from this ritual, it was an intentional and well organized act, reportedly abiding by the instructions of the MP who initiated the ritual. He had warned that no women should be allowed inside so as not to pollute the state fire. ${ }^{15}$

The Presidential Decree that legitimated this ritual, repeated in 2012, is but one in a long list of similar decrees issued by the Mongolian Presidents, covering a range of cultural and religious practices including advising every citizen to worship the Morin Khuur (horse-head fiddle), ${ }^{16}$ the Secret History of the Mongols $^{17}$ and the State Flag ${ }^{18}$ and placing them in honored locations in every household or office, worshipping mountains ${ }^{19}$ and conducting religious rituals to that effect, revering the Great Chingghis Khaan and learning from his teachings, conducting state ceremonies to pay due respect to Chingghis Khaan ${ }^{20}$ and calling onto "every Mongolian person who reveres the national origins" to celebrate the $2220^{\text {th }}$ anniversary of the Mongol State. ${ }^{21}$ In 2007, the Government approved a similar regulation requiring every citizen to conduct genealogical records and

14 Presidential Decree (2011.12.26) on Lighting the Mongol State Fire.

15 The MP reportedly stated that he had brought in rocks from the Burkhan Khaldun mountain and women and not right to step into the space marked by these rocks and that women's presence would pollute the state fire. Parliamentary media reported that the previous day they received instructions to only send in male journalists as women would not be allowed. Exclusion of women, including women MPs, was highly organized and premeditated.

16 Presidential Decree (2002.02.11) on Respecting and Promoting the Morin Khuur.

17 Presidential Decree (2004.02.18) on Eternally Revering and Respecting the Secret History of the Mongols.

18 Presidential Decree (2011.07.09) on Spreading the Initiative to Respect the State Flag of Mongolia.

19 Just one example: Presidential Decree (2010.09.20) on Worshipping the Burkhan Khaldun Mountain.

20 Presidential Decree (2007.05.24) on Respecting Great Lord Chingghis Khaan, learning from his many teachings, and showing state respect.

21 Presidential Decree (2010.10.15) on Celebrating the $2220^{\text {th }}$ Anniversary of the Mongol State. 
charging local governments with a duty to oversee the implementation thereof. ${ }^{22}$

Whatever the focus, these acts have one thing in common: they are motivated by and reinforce the growing Khalkha-centric ${ }^{23}$ ethno-nationalist movement and inhibit the development of a humane, egalitarian and inclusive democratic culture. They violate the constitutional principles of the secular state and freedom of religion, intrude on the freedom of conscience, and constitute discrimination on the basis of ethnicity, religion, gender and sexual orientation.

A few words on basic freedoms

It is generally believed that Mongolia has no serious issues with the basic freedoms and civil and political rights. However, it appears that the picture may differ drastically depending on the location, social status and civil society branch. Thus, marginalized groups such as LGBT individuals, women in prostitution, artisanal miners, adults and children living off the streets, the poor, etc. may be denied their basic rights on a regular basis. As a group of artisanal miners from Zaamar (Tuv aimag) reported during a training session in 2011, their reality is more akin to that of the Jewish ghettoes during World War II than the Ulaanbaatarbased CSOs. Their stories reveal systematic and long-standing (over 5 years) violations of their human rights by local and central governments, police, and private security of the mining companies. Trade unions and civil society activists also stress that the labor and other rights of people working in the informal sector are routinely violated.

\section{Legal framework for $\mathrm{NGOS}$}

While the NGO Law is indeed rather liberal, it was somewhat weakened by subsequent legal reforms and is regularly undermined in practice by state institutions. Thus, the State Registration Bureau has often violated the NGO law by refusing to register NGOs (e.g. the LGBT center) or imposing extra-legal requirements (such as not including foreign words or abbreviations in the NGO name or using certain words such as "advocacy" or "influencing policy" in the description of activities). Getting registered therefore often becomes a timeconsuming and stressful undertaking.

22 Government of Mongolia, "Regulation on Conducting Genealogical Records" (2007.10.03). The text goes as far as to mention how "illegitimate" or "out-of-wedlock" children should maintain such records.

23 The majority ethnic group in Mongolia are Khalkha. For more on Mongolian nationalism, see: Uradyn E. Bulag, Nationalism and Hybridity in Mongolia (Clarendon Press, Oxford: 1998); Undarya Tumursukh, "Fighting over the Reinterpretation of the Mongolian Woman in Mongolia's Post-Socialist Identity Construction Discourse," East Asia 19, no. 3 (Fall 2001), 119-146; Undarya Tumursukh, "Masculine Constructions of National Identity and Man-Made Images of the Mongolian Woman in Post-Socialist Mongolia" paper published on the web by the Center for Russian, Central and East European Studies and the Allen and Joan Bildner Center for the Study of Jewish Life, Rutgers University, NJ, USA, http://www.rci.rutgers.edu/ culdemsm/ Index.htm. 
More serious threats are currently posed by the taxation and insurance laws. According to the tax law, all entities must deduct income tax from all cash payments they make. Further, according to the insurance law, all entities must deduct $10 \%$ personal contribution for social insurance and pay $11 \%$ of the employer's contribution for all cash payments for which they deducted income tax. In practice, this has meant that NGOs have been required to deduct $10 \%$ income tax $10 \%$ personal contribution to social insurance and somehow pay $11 \%$ employer's contribution to social insurance even when paying the taxi driver, occasional service-providers (e.g. translation or printer maintenance), and meals and transportation allowances for volunteers. These legal provisions are impossible to implement in the event of, for example, taxi drivers, and significantly raise administrative costs for NGOs, who already operate under significant pressure from their donors to keep their administrative costs below $10 \%$ or sometimes even $5 \%$. A number of NGOs have since been inspected by taxation and insurance offices and forced to pay penalties for non-compliance with the law.

It needs to also be mentioned that Mongolia still has not reinstated the 1997 provisions for tax deductions to support philanthropy, which limits NGOs' potential to raise funds domestically. Also while NGO incomes are tax-exempt, they are not exempt from real estate taxes, which impose additional burden on NGOs that own buildings such as shelter houses.

\section{Values}

This dimension looks at the values promoted and practiced by civil society. The score of 1.7 reflects overall positive trends in the value basis of the Mongolian civil society. Overall, CSOs, especially NGOs and social movements, were found to display a significant degree of commitment to promoting democracy, government accountability, nonviolence, gender equality,

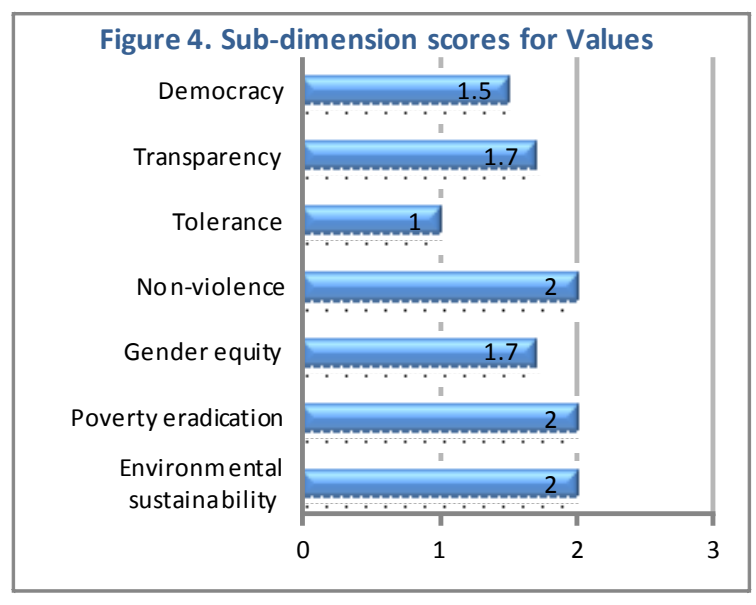
poverty alleviation and environmental protection. The study assessed that internal practices along these values were somewhat weaker. Political parties, apartment 
owners' unions and inherited mass organizations, including trade unions, were generally regarded as less democratic and transparent and, in some cases, prone to corruption and intolerance based on political affiliations.

The lowest score was assigned to the tolerance sub-dimension, which mainly reflected the high level of intolerance based on political affiliations. In general, this was the hardest sub-dimension to assess as the tolerance as a concept was not and is still not widely used or understood. Generalizing the level of tolerance for all of civil society would be difficult as human rights community displays not only a high level of tolerance for but acceptance and appreciation of differences based on ethnicity, origin, age, gender, sexual orientation, etc., whereas ethnonationalist groups are at the other extreme, displaying high level of not only intolerance but hatred of others based on gender, ethnicity, sexual orientation and lifestyle. While celebration of diversity and emphasis on inclusiveness have become an integral part of the human rights and women's rights NGO culture, the majority of the civil society field is likely to score rather low on the tolerance sub-dimension.

Non-violence deserves special mentioning. Mongolian civil society, with the exception of ethno-nationalist groups, has been largely non-violent. However, in the past some environmental groups and indigenous herder groups have resorted to violence out of frustration and despair, having repeatedly collided with oppressive state institutions, corrupt government and hostile mining companies. Unfortunately, these types of violent confrontations over resources are likely to mount unless the government and corporations take appropriate measures to mitigate social and environmental impacts of mining and, most importantly, ensure that mining contracts are fair to the local population.

The human rights and women's rights community pays significant attention articulating and upholding highest ethical standards. The following are the key values and principles for this sub-field:

- Independence from the state (it does not mean being against the state, it also allows for cooperation with the state but from an independent position)

- Independence from narrow economic interests and political forces (mainly corporations and political parties)

- Non-violence (physical, psychological and verbal)

- Transparency - first and foremost vis-a-vis our citizens

- Accountability - first and foremost to citizens (then to our donors and other parties)

- Focus on supporting and empowering the most marginalized, the least powerful groups

- Democratic, horizontal, open organizational structures 
- Non-discrimination (based on gender, age, sexual orientation, origin, income, etc.)

- $\quad$ Ethical process towards ethical means

- Self-awareness, commitment to personal change in parallel to promoting social change

\section{Impact}

This dimension looks at the extent to which civil society is active and successful in fulfilling several essential functions within Mongolian society. The score of 1.4 indicated a somewhat low level of impact especially compared to the efforts exerted by the CSOs.

Figure 5. Sub-dimen sion scores for Impact

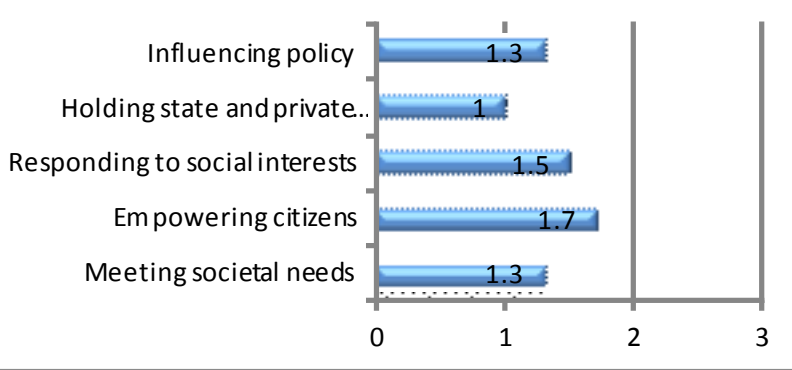

CSOs were especially active and impactful in raising awareness and building capacity of various groups, especially on women's rights and gender equality. They were also more successful in policy advocacy but not so much in holding the state and corporations accountable. CSOs also provided crucial services to underprivileged and marginalized citizens but most of these services were limited in scope and inconsistent due to limited funding. There were important examples of success but CSOs were generally unable to convert them into direct impact or scale up, due to environmental barriers.

The latest encouraging example of impactful work is the advocacy conducted in 2012 by the "All for Education!" National Civil Society Coalition to prevent, successfully, legal reforms to support the elitist Cambridge education program, which would have a disastrous effect on the quality of public education and social equity. The coalition not only managed to convince a sufficient number of MPs not to pass amendments to the education law proposed by the Minister of Education, but inspired many education stakeholders - students, parents, and teachers - that they can effectively struggle for the improvement of the education system and policies.

With improved environment, more favourable funding, and positive attitude of state institutions, civil society impact can easily be much greater and more sustainable. Approving and implementing the State Policy Concept on Civil Society Development, therefore, is a necessary step if the Mongolian government wishes to boost social development. 


\section{Conclusion}

Mongolian civil society has come a long way since its emergence in the early 1990s. While the field is broad and defies generalizations, the human rights/ women's rights and pro-democracy advocacy NGOs have matured substantially, clearly articulating their values and principles, maintaining ethical practices, effectively building new forms of democratic structures and organizations, fostering solidarity and movement-building for progressive social change. They have been able to sustain their work in a largely unfavourable political, economic, cultural and financial environment, without adequate support from either the government or international community. However, at the threshold of a new decade wrought with risks as well as opportunities due to the mining boom, the field is not adequately equipped to play the crucial role it needs to play - to empower citizens and communities to stand up against corruption and human rights violations, to hold government and private sector accountable and chart a more equitable course of development. To play this role that only civil society can play, consistent policy measures are needed to strengthen the field. 